\title{
O SOL, A PEDRA, OS HOMENS: ISTO É UM STONEHENGE? VESTÍGIOS MEGALÍTICOS- SÍTIO AP-CA-I8
}

\author{
Walderi Gouveia Rodrigues ${ }^{1}$ \\ Vinicius Maione ${ }^{2}$
}

RESUMO: O texto tem a pretensão de debater sobre a trajetória de formatação do chamado "Stonehenge" do Amapá, quanto a sua nomeação, buscando interpretar o processo que levou a afirmação por parte da mídia de tal pressuposto. Enfatizando a importante contribuição dos recentes trabalhos para o desenvolvimento de uma arqueologia na Amazônia especialmente no extremo norte do amapá, no sítio APCA I8. A partir de temas como o "cachimbo de Magritt" problematiza dentro da filosofia que funda a arqueologia, os movimentos do discurso sobre institucionalização de uma politica Eurocêntrica, buscando abordar a descolonização do processo de interpretação dos achados arqueológicos no município de Calçoene, apontando o encontro de uma leitura que envolva as perspectivas ameríndias.

Palavras-chave: "Stonehenge do Amapá”. Arqueologia. Solstício. Persperctivismo.

ABSTRAT: The text intends to debate the formatting trajectory of the so-called "Stonehenge" of Amapá, regarding its nomination, seeking to interpret the process that led to the assertion by the media of this assumption. Emphasizing the important contribution of recent works to the development of an archeology in the Amazon, especially in the extreme north of Amapá, at the AP-CA I8 site. Based on themes such as the "Magritt pipe", he problematizes within the philosophy that founds archeology, the movements of the discourse on institutionalization of a Eurocentric policy, seeking to approach the decolonization of the process of interpretation of archaeological finds in the municipality of Calçoene, pointing out the meeting of a reading that involves Amerindian perspectives.

Keywords: "Stonehenge of Amapá". Archeology. Solstice. Perperctivism.

\section{INTRODUÇÃO}

Não sei se essa é a regra para algum pesquisador; mas, no nosso caso uma pesquisa sempre se inicia por uma leitura que lembra um fato vivido ou imaginado ao longo da trajetória da vida; claramente parece uma distorção proposital (uma história desvirtuada), mas não, é uma "perspectiva”. Levy Strauss sem seu livro Mito e Significado (1978), nos contempla com uma frase brilhante: "cada um de nós é

\footnotetext{
${ }^{\text {I }}$ Acadêmico de licenciatura em filosofia da Universidade do Estado do Amapá-UEAP

${ }^{2}$ Professor doutorando da Cadeira de Filosofia da Universidade do Amapá-UEAP
} 
uma espécie de encruzilhada onde acontece coisas”. E coisas sempre acontecem aos olhos do observador e mais a frente ressalta intimamente: "logo que acabam de me atravessar, sinto-me vazio e em mim nada fica" (idem). Logo, traçamos um caminho onde o recorte do conhecimento possa ser estudado cientificamente. Desta forma, foi nossa pesquisa no campo na área da filosofia com o pensamento ameríndio e assim pretendo agora alcançar mais um degrau desta jornada.

A arqueologia sempre esteve presente em minhas representações do mundo; desde minha infância, pois, temos uma cultura impregnada de mitos dos povos que habitaram a Amazônia e um imponente forte em frente a cidade de Macapá-AP, sempre nos mostrando uma parte viva da história da colonização portuguesa na América. De forma que um simples rabisco ou uma anotação de um trecho de um texto de um autor, pode mudar um caminho ou um planejamento e nesta ocasião o de CABRAL, M. P.; e SALDANHA, um trabalho que tem como título: UM SÍTIO, MÚLTIPLAS INTERPRETAÇÕES: O CASO DO CHAMADO “STONEHENGE DO AMAPÁ”, 2009; neste, busco solucionar “inquietações" que são movidas pela leitura e pelas conjecturas das entrelinhas:

[...]Não podemos falar em "abrir" um sítio à interpretação, simplesmente porque é impossível fechá-lo à interpretação. Todos nós, arqueólogos ou não, estamos interpretando sítios quando os visitamos. $O$ que nós precisamos não é abrir os sítios à interpretação; o que nós precisamos é abrir nossos projetos a outras interpretações. E abrir nossas práticas, nossas teorias e nossos discursos aos outros pode ser o início da construção de arqueologias realmente híbridas. " (CABRAL, M. P.; SALDANHA; 2009)

Começam assim nossas indagações.

Para começarmos devemos ter em mente que o Estado do amapá é rico em terras “exploráveis" pela arqueologia; a exemplo temos: Cerâmica Maracá/Cunani, Parque Arqueológico do "Solstício" localizado no município de Calçoene, Mazagão Velho e suas ruinas, a fortaleza de São José de Macapá, Mazagão velho, o mocambo do Curiaú, etc. E, debruçar-se em um projeto de pesquisa onde a variedade de possibilidades de objetos pesquisáveis, disciplinas aplicáveis a arqueologia são muitas; sabemos é um leque de probabilidades infinitas e de resultados conjecturáveis. Embora, “...pretender reconstruir um passado cuja história não temos meios de atingir ou querer fazer a história de um presente sem passado..." (Levy Strauss, Antropologia Estrutural, 2017, p.15) é um trabalho que só a arqueologia com 
seus meandros, podem em algum momento dar uma luz no passado considerando "todos os indícios da presença ou atividade humana em determinado local” (Prous, p.25, 1992).

O grande desafio nesse artigo é de compreender a possibilidade de uma conversa no cerne da narrativa filosófica da arqueologia com uma sociedade que de modo intencional ou não nos deixou fragmentos de sua passagem no tempo e no espaço e onde o que temos de concreto e palpável são objetos descartados (vestígios em sítios arqueológicos) e leve apanhados de mitos e fragmentos de história da perspectiva do colonizador europeu. Não temos (ainda decifrados), por exemplo como em outras culturas literaturas conclusivas referentes a escrita ou se algum dia vamos ter algo análogo a tradução dos Códices Maias. Assim, é certo, "para compreender a história, não basta saber como as coisas são; é preciso saber como vieram a ser o que são...” (Levy Strauss, Antropologia Estrutural, 2017, p. 21) e encontrar meios ou alternativas para a melhor leitura dos "indícios da presença ou atividade humana em determinado local" (Proust, 1992).

Destarte, é imprescindível a busca por um objeto de análise "palpável” no sentido mais profundo das ciências arqueológicas, que nos proporcione alternativas viáveis no campo de pesquisa e que possam de alguma forma nos apresentar meios e alternativas averiguáveis dentro de um contexto racional e em muitas ocasiões pragmáticos; embora nas ciências a qual se desenvolve o contexto existam margem para pressuposições que corroborem com o objeto pesquisável, ainda que "para ser legitima, a pesquisa deve restringir-se a uma pequena região com fronteiras claramente definidas e as comparações não poderão ser entendidas para além da área escolhida como objeto de estudo"(idem, P. I9). Assim, penso, os trabalhos arqueológicos em relação a grande massa da sociedade é como (comparando sistematicamente) um vestígio "enterrado" onde não se tem informações que se destaquem de outros vestígios humanos atuais. São necessários discursos repetidos para que de um lado o estado se sensibilize da necessidade de coleta de dados e informações mais precisas; de outro, em contrapartida, para atingir a sociedade são necessários outros meios que vão da inter-relação arqueólogo/comunidade a divulgação nas grandes redes de mídia (embora em algumas situações adversas a mídia transforme ou engrandeça as revelações ou mesmo a torne pequena dado a sua 
grandiosidade como descoberta arqueológica) e isso é o insiste Cabral e Saldanha. A arqueologia atinge este objetivo sempre?

Se o arqueólogo tem um papel ativo como produtor de conhecimento, isso obviamente significa que a produção de conhecimento não é uma tarefa automática. Pelo contrário, produzir conhecimento arqueológico é um processo interpretativo, é a construção de um discurso: transformar coisas em palavras, dar sentido às coisas através das palavras. Então, a relação entre as coisas e o texto é feita pelo arqueólogo que, deliberadamente ou não, está dando valores, significados, às coisas e a seu texto." (CABRAL, M. P.; SALDANHA; 2009)

Assim sendo, vamos "a pintura do Cachimbo de René Magritte (bem interposto no texto) "entre a linguagem e as coisas, existem os significados" (idem). Logo, nos parece que como disse Foucault (2004) em relação ao quadro de Magritte "a distância dos dois elementos, a ausência de letras em seu desenho, a negação expressa no texto, manifestam afirmativamente duas posições. ", e assim, para CABRAL, M. P.; SALDANHA; (2009) o resultado final é a produção do discurso fundamentado nas teorias arqueológicas que é "escrita, articulada, é discursiva", então enfatiza relacionando a obra de Magritte, "se não é um cachimbo, o trabalho de escavação não é o passado".

Assim, existe algo a mais no quadro de Magritte. Existe algo a mais na arqueologia? De certo, não é um cachimbo, mesmo que o vestígio encontrado seja um cachimbo indígena. Então a pergunta: o sítio AP-CA-ı8 é um "Stonehenge"?

CABRAL, M. P.; SALDANHA; (2009) nos informa como em 2005, dado certas circunstancia o sítio AP-CA-18, tomou a proporção de interpretação midiática e "mítica", surgindo assim posteriormente a hipótese de um "Stonehenge".

O que ocorreu foi que em Novembro de 2005, uma equipe de pesquisadores e técnicos do Estado estava na região de Calçoene fazendo alguns trabalhos. Uma dessas pessoas convidou a equipe para visitar um local onde havia umas pedras fincadas no chão. Esse era o sítio AP-CA-I8, na época conhecido basicamente só pela população local e uns poucos visitantes. É um sítio belíssimo. É uma estrutura circular de grandes megalitos, com 30 metros de diâmetro. Nas escavações, a nossa percepção é de contextos cerimoniais: enterramentos, oferendas, visitações.

Além da impressionante estrutura que eles viram, um dos participantes, Elias José Ávila, meteorologista do IEPA, teve a sensibilidade de observar em um dos blocos um possível alinhamento com o sol durante o Solstício, até aí apenas como hipótese, que depois foi comprovada. Então o botânico Benedito Rabelo, na época Diretor do Centro de Ordenamento Territorial do IEPA, escreveu um relatório sobre essa situação. (CABRAL, M. P.; SALDANHA; 2009)" 
Como disse Foucault "O desenho de Magritte (...)é tão simples quanto uma página tomada de um manual de botânica: uma figura e o texto que a nomeia”. De tal modo, podemos dizer algo ou o mesmo do Sítio AP-CA-I8, que os megálitos são a perfeita representação de um "Stonehenge", devendo assim ser classificado e tratado como tal? Assim sendo, o que caracteriza um "Stonehenge"?

\section{O SOL}

Para um meteorologista observar o céu da perspectiva de um fenômeno possível e viável com seus aparelhos modernos e suas técnicas auxiliadas por informações advindas de satélites dispostos no espaço são extremamente mais fáceis que para os povos que viveram na Amazônia antes da chegada dos europeus, que seguramente necessitavam de anos de observação do céu. Porém, seria possível determinar que dado objeto está alinhado a um determinado evento da natureza apenas "em poucas linhas"? Ou haveria necessidade de uma observação mais prolongada, dado que as naturezas e as técnicas aplicáveis foram diferentes? Seria necessário compreender o sitio por completo ou apenas parte dele já o definiria como um "lugar de observação de eventos"? Ou um lugar para cerimonial e enterrar os mortos? Estas inquietações advêm de um simples questionamento.

Segundo a Revista Pesquisa Fapesp com a reportagem intitulada "Pedra do Sol”, no final do século XIX esteve no norte do amapá Emílio Goeldi, que teve como um de seus objetos de investigação o encontro com "os grandes blocos de rochas"; posteriormente outros pesquisadores como Curt Nimuendajú (década de 1920) ${ }^{3}$, Betty Meggers e Clifford Evans (década de 1950), posteriormente a estes personagens da arqueologia no Brasil a região foi esquecida.

No ano de 2005 chegam ao Estado o casal de arqueólogos Mariana Petry Cabral e João Darcy de Moura Saldanha e em um de seus projetos de pesquisa

\footnotetext{
3 "Apesar de ser uma área pesquisada desde o final do século XIX, as informações arqueológicas sobre o litoral norte do Estado do Amapá ainda são extremamente fragmentárias. Até meados do século $\mathrm{XX}$, os dados eram referentes a pesquisas de caráter exploratório, visando reconhecer os fenômenos arqueológicos da região e obter exemplares para coleções de museus. É neste quadro que se inserem os trabalhos de Emilio Goeldi (1905) e Curt Nimuendajú (2000, 2004)." (CABRAL, M. P.; SALDANHA, J. D. M.; 2008)
} 
incluem o sítio AP-CA-I8 entre outros de grande importância para a arqueologia no Amapá.

Rego Grande e outros sítios com megálitos exibem traços de terem sido usados também como cemitérios, outra característica típica desse tipo de estrutura pré-histórica. Urnas funerárias feitas no estilo cerâmico aristé, marcado por desenhos vermelhos sob um fundo branco ou pontuado por gravuras feitas na argila ainda úmida, foram encontradas nesses locais. Pedaços de vasos decorados, achados junto às urnas, indicam que os mortos podem ter sido enterrados ao lado de oferendas. "Os sítios com grandes megálitos devem ter sido destinados às pessoas mais importantes da tribo", afirma Saldanha. O problema é que cerâmicas desse estilo foram igualmente encontradas em sítios pré-históricos que não exibem monumentos de pedra. Comum em todo o litoral norte do Amapá e na Guiana Francesa, a elaborada cerâmica aristé deixou de ser produzida depois da chegada do europeu às Américas e, segundo Mariana, sua confecção não pode ser associada a nenhum povo indígena atual da região. " (revistapesquisa.fapesp; 20II)

O que propomos acentuar neste estudo em alguma medida é o ponto de partida para além do cachimbo de Magritte, ou das teorias de Foucault sobre a tela intitulada "isto não é um cachimbo", perguntar para a epistemologia arqueológica se, "isto é, um "Stonehenge"?

E o que é um "Stonehenge"?

MBROISI, Margaret; MARTINS, Simone. (202I), nos dizem que:

O nome Stonehenge vem das palavras do inglês arcaico "stone" = pedra e "henge" = eixo. O lugar é talvez o mais famoso do Reino Unido e se trata de um alinhamento megálito do período Neolítico, localizado na planície de Salisbury, próximo a Amesbury, no condado de Wiltshire, no Sul da Inglaterra."

No trabalho "Stonehenge. História das Artes" (202I); a pergunta que as autoras fazem é sobre a capacidade de força e inteligência do que elas chamaram de "homem primitivo" - sem levar em conta que os homens modernos teriam dificuldade de mover pedras desta natureza em relação a distância e peso sem o auxílio de maquinas motorizadas - e o motivo que os levou a construção e o posicionamento das pedras. A primeira das alternativas seria para acompanhar ou marcar um evento, seja ele astronômico ou ritualístico. No caso astronômico seria para marcar eventos como o solstício de inverno.

SOLSTÍCIO: Um evento astronômico que acontece duas vezes por ano, quando a posição aparente do Sol no céu atinge seus extremos mais ao norte ou sul. O solstício de verão é marcado por o dia mais longo. A data varia entre 20 e 22 de junho, dependendo do ano. O solstício de inverno é marcada por o dia mais curto, ou 2I ou 22 de dezembro de cada ano. Em Stonehenge, parece que ambos os eventos foram marcados pela disposição 
das pedras e da posição da Avenida. Visto a partir do centro do círculo de pedra, o sol nasce ao lado da Pedra do Salto no solstício de verão e define entre as pedras do Trilithon mais alto no solstício do inverno. "(idem)

Deixaremos um pouco o "Stonehenge” da Planície de Salisbury-Inglaterra e tomemos os marcadores amapaenses - Brasil. Voltemos a pergunta inicial é ou não um "Stonehenge"? Se afirmativo, o que levou a construção de tal monumento monolítico? Qual o objetivo?

Então partindo do princípio de que "Stonehenge" é uma estrutura composta por uma estrutura de pedras formando um "circulo"; um referencial bem simples. Podemos iniciar por este ponto. Stonehenge é formado por enormes blocos de pedras organizados em forma circular. Então concluiríamos apressadamente: Isto é aquilo.

No entanto, levando em consideração embora ainda não concluso alguns fatores que diferenciam o" Stonehenge" Inglês dos achados no município de Calçoene-AP como:

- Topografia espacial;

- Relação do nativo da Amazônia com a natureza/cultura;

- Conhecimento acumulado durante toda permanência na área;

- O entendimento de Cultura/natureza baseando na proposta do multinaturalismo ou perspectivismo ameríndio;

A interação com seus mitos;

Poderíamos colocar em suspensão a afirmação: “que isto é aquilo”. Existem outras razões e outros conhecimentos que diferenciam em muitos as civilizações eurocêntricas e as ameríndias, levando em consideração a arqueoastronomia, antropologia, historiografia, e a arqueologia que vem repensando suas propostas anteriores para a Amazônia, etc.

\section{A PEDRA FILOSOFAL}

O perspectivismo proposto antropólogo Eduardo Viveiros de Castro (2002, 2002, 1996) e Tânia Stolze Lima (1996, 2012) abre caminho para uma releitura das informações contidas nos trabalhos de arqueologia da região amazônica. Vejamos então como conceitua Viveiros de Castro o Perspectivismo Ameríndio. 
A idéia básica (que não é uma idéia simples) do perspectivismo, tanto o indígena como seu análogo ocidental, é que toda posição de realidade especifica um ponto de vista, e que todo ponto de vista especifica um sujeito - nessa ordem. No caso indígena, tal especificação é em primeiro lugar uma especiação, pois a diferença de ponto de vista entre humanos e não-humanos é ali uma questão fundamental, e a realidade assim posta compreende a realidade reflexiva do sujeito, individual ou coletivo, pois toda posição de auto-identidade envolve a "perspectiva do Outro" (Taylor 1993: 673) como um momento constitutivo. O perspectivismo implica, portanto, a alteridade: a diferença como ponto de vista, o ponto de vista como diferença... ((VIVEIROS DE CASTRO, 2002, p. 132).

A "pedra filosofal" que pode abrir um caminho ou melhor ver em outra perspectiva todos os achados arqueológicos (e que já foi experienciado) a ideia de que os nativos da Amazônia tratam de forma diferente sua relação com os mundos; pois, é concepção, comum a muitos povos o mundo ser habitado por diferentes espécies de sujeitos que apreendem o mundo de perspectivas diferentes (Viveiros de Castro, 20II, p347). Assim, estas visões de mundo podem abrir caminhos para o alinhamento entre o que falta e o que está evidente. Aos olhares de nativo seriam as pedras do sítio AP-CA-I8 um "Stonehenge"?

Para o homem pré-histórico, o firmamento tinha um significado bem
diverso do que, imaginamos, tem para nós, homens modernos. Para eles,
sem a poluição luminosa das grandes cidades, a harmonia da imensa
abóbada noturna de pontos luminosos situada imediatamente acima de
suas cabeças - bem como a Lua e, durante o dia, o Sol e sua fonte de luz
(que aquecia e, igualmente, cegava) - regia e ordenava a sucessão de
fenômenos que ocorriam no espaço terrestre em que viviam, tornando-se,
assim, nessa visão de mundo, o componente principal de sua existência. "
(Prazeres, 20o8) Lembrando aqui o que escreveu Lévi-Strauss que os índios de Puebla acreditam que as peças de cerâmica possuem alma, seriam seres com sujeitos e adquirem características humanas assim que são transformadas em matéria para a confecção de uma "coisa" de utilidade, esse processo Acontece antes de serem lançadas ao fogo para serem cozidas, assim, quando um pote se quebra durante o cozimento é sua alma que foge, escapa. (LÉVI-STRAUSS, 1985). E se concluirmos como Almeida (2008) os povos indígenas tinham a visão comunitária e sagrada da natureza pois "as montanhas, os lagos, os rios, as pedras, as florestas, os animais e as árvores têm um algo significado, todos vivem". Tanto o céu como os objetos têm outra finalidade ou utilidade porque

\section{${ }^{4}$ Adeumá}

rio prazeres é presidente da Sociedade Astronômica do Recife e presidente fundador da Associação Astronômica de Pernambuco. 
vivem, se assim podermos conjecturar todo o sítio arqueológico a qual este artigo se reporta seria na perspectiva nativa uma profusão de seres e coisas.

\section{OS “HOMENS"}

Os arqueólogos, os antropólogos, os historiadores e os outros afins interessados nos resultados postulados das pesquisas no sítio AP-CA-18 como no caso aqui de Manoel Calado.

Especialista em megálitos, em especial os do Alentejo, o arqueólogo português Manoel Calado, da Universidade de Lisboa, concorda com a hipótese de que as pedras inclinadas do Rego Grande podem ter sido dispostas dessa maneira para marcar a observação, na linha do horizonte, de eventos astronômicos simples, de caráter cíclico, como a trajetória do sol solsticial. "Não tenho nenhuma dúvida (disso)", diz Calado, que já esteve no Amapá para conhecer as estruturas líticas desse sítio, mas não faz parte do grupo de pesquisa dos brasileiros. "Esse é um dos aspectos que tornam os megálitos amazônicos muito semelhantes aos da Europa." Para ele, a construção desse tipo de estrutura pode ter sido realizada no Amapá num momento em que as tribos locais passavam por um processo de sedentarização e de eclosão ou desenvolvimento da agricultura. Era preciso estar fixo à terra para alterar a paisagem com estruturas como os megálitos.” (revistapesquisa.fapesp; 20II) (grifo nosso)

Nos parece em alguma medida que traduzir um evento de construção

promovido pelos ameríndios com uma visão eurocêntrica comparativa e reduzila ao espectro de um experimento inocente é duvidar da capacidade construtiva e belicosa de toda uma geração de "homens" que viveram nas inóspitas terras da Amazônia antes da chegada dos europeus na América.

\section{O SOL, A PEDRA, OS HOMENS: isto é um Stonehenge? (A título de considerações gerais)}

Vejamos então que "Hilbert também propôs uma potencial ligação histórica entre os índios Palikur, habitantes da costa norte do Amapá, e os vestígios arqueológicos associados à Fase Aristé" (Hilbert, 1957; ibidem CABRAL, M. P.; SALDANHA, J. D. M.; 2009). Porém, isso não definiria o pertencimento da perspectiva dos achados, pois eles (os achados) não produzem o efeito da fala, é silencioso. Então, fala, se não, pelas interpretações dos arqueólogos que partindo das teorias cientificas fazem um "extrato" do que poderia estar demarcado nos achados e transforma usando sua dialética em um texto correlato ao que a ciência predispõe ser uma variante assertiva. Se Lévi-Strauss (1978) nos diz que éramos 
poucos durante centenas de anos e que como pequenos grupos desenvolvemos características grupais diferente um dos outros, por conseguinte, podemos aventar que europeus são

Certamente o que está em jogo neste artigo não são as motivações ou as comprovações cientificas ou se o discurso científico é falso ou verdadeiro em tal enunciado; porém, como o pensamento de Heráclito parece afirmar qualquer discurso pode ser falso ou verdadeiro ou o contrário, ao mesmo tempo ou não

\section{REFERÊNCIAS BIBLIOGRÁFICAS}

ALMEIDA, Fábio Vaz Ribeiro (org), guia para a formatação em gestão de projetos indígenas. Brasília: paralelo $15,2008$.

CABRAL, M. P.; SALDANHA, J. D. M.; Um sítio, múltiplas interpretações: o caso do chamado "Stonehenge do amapá", Revista de Arqueologia, v.22, n.I, (jan-jul.20o9): II5 I23, 2009.

Paisagens megalíticas na costa norte do Amapá, Revista de Arqueologia, 21: 09-26, 2008.

A longa história indígena na costa norte do Amapá», Anuário Antropológico [Online], v.39 n.2 | 2014, posto online no dia or agosto 2017, consultado o 27 abril 2021. URL: 〈http://journals.openedition.org/aa/126r >; DOI: 〈https://doi.org/ I0.400o/aa.I26r >

FOUCAULT, Michel; Isto não é um cachimbo; Título Original: Ceci n'est pas uue pipe; Tradução: Jorge Coli; Data de digitalização: 2004; primeira edição impressa: 1973.

Flavia P. Lima; Priscila Faulhaber Barbosa; Marcio D’Olne Campos; Luiz Carlos Jafelice; Luiz Carlos Borges; Relações céu-terra entre os indígenas no Brasil: distintos céus, diferentes olhares; História da Astronomia no Brasil - Volume I.

LÉVI-STRAUSS, Claude. A oleira ciumenta. São Paulo;Ed. Brasiliense , I985.

Mito e Significado, Edições 7o, Lisboa, Portugal, 1978.

Tristes trópicos, Companhia das Letras, São Paulo,1996

Antropologia Estrutural, Tradução: Beatriz Perrone-Moisés, São Paulo:

Ubu Editora, 2017.

MBROISI, Margaret; MARTINS, Simone. Stonehenge. História das Artes, 2021. Disponível em: 〈https://www.historiadasartes.com/nomundo/arte-naantiguidade/pre-historia/stonehenge/>. Acesso em o6 Dez 202I. 
PROUS, André. Arqueologia brasileira; Brasília, DF: Editora; Universidade de Brasília, 1992.

VIVEIROS DE CASTRO, Eduardo; A Inconstância da alma selvagem - e outros ensaios de antropologia; São Paulo; Cosac Naify; 20 Ir.

$<\mathrm{http} / /$ revistapesquisa.fapesp.br/>as-pedras-do-sol/; acesso em: 05/12/2021; I8:12 h; Edição I86 ago. 2011. 